56 Jahren. Sein Engagement im Rahmen der Jägerorganisation in der Bundesrepublik Deutschland fand bereits zu seinen Lebzeiten hohe und verdiente Anerkennung, sein Tod bedeutet deshalb für die Jäger unseres Landes und den Deutschen Jagdschutz-Verband einen herben, unersetzlichen Verlust.

Aber auch wir Jagdwissenschaftler trauern um diesen aufrechten Mann. Sein Eintritt in das Kuratorium der ehemaligen Stiftung „Forschungsstelle für Jagdkunde und Wildschadenverhütung، im Jahre 1975 und seine weitere Mitgliedschaft in dem Beirat des 1976 verstaatlichten Instituts konnte nur als ein Gewinn bezeichnet werden. Stets war sein Wirken von menschlicher Güte, Fairneß und dem Streben nach Objektivität bestimmt und damit von Eigenschaften, die der Wissenschaft im besonderen Maße zur Ehre gereichen.

Als Förderer der jagdlichen Belange allgemein, speziell aber auch der Fachliteratur und Jagdkunst über die Grenzen seines Vaterlandes hinaus, und als guter, sich aufopfernder Mensch, so wird er in unserer Erinnerung weiterleben.

ERHARD UECKERMANN

\title{
Verleihung des Kulturpreises 1980 des Deutschen Jagdschutz-Verbandes an Prof. Dr. Walter Rieck
}

Anläßlich der repräsentativen Hauptversammlung des Deutschen Jagdschutz-Verbandes in Lüneburg am 10. Mai 1980 erhielt Prof. Dr. WALTER RIEcK den Kulturpreis 1980 des Deutschen Jagdschutz-Verbandes. Damit wurde sein Wirken auf dem Gebiet der Jagdwissenschaft über nahezu vier Jahrzehnte gewürdigt. Wir freuen uns, daß der 1979 anläßlich der Hauptversammlung in Bonn erstmalig verliehene Kulturpreis nach Prof. em. NüssleIN wiederum für einen Jagdwissenschaftler vorgesehen wurde und gratulieren herzlich.

ERHARD UECKERMANN

Verleihung des Kulturpreises 1980 des Deutschen Jagdschutz-Verbandes an Prof. Dr. WaLTER RiEck, links Präsident Egon

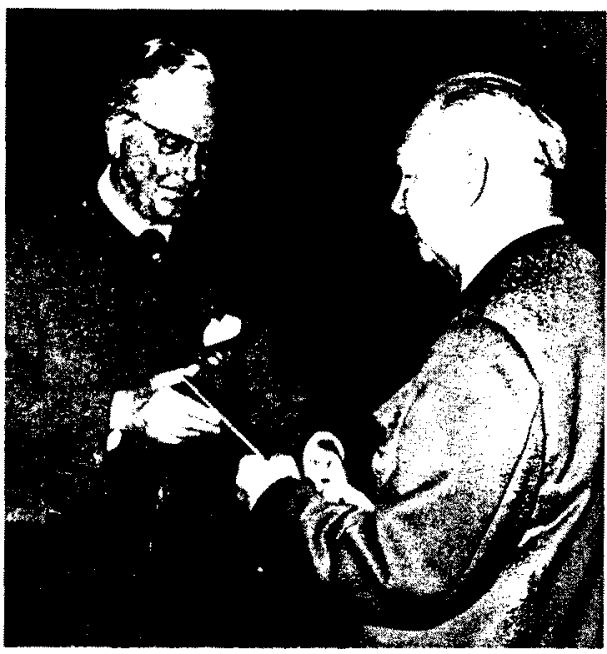
ANHEUSER

\section{Professor Dr. Fritz Ernst 80 Jahre}

Am 28. Juli 1980 vollendete Oberregierungsforstrat Professor Dr. FrrTz ERNST in Eglharting bei München das 80 . Lebensjahr.

Professor ERNST hat - was im Rahmen dieser Zeitschrift vor allem interessiert - an der Universität München seit 1956 bis zu seinem Ausscheiden im Jahre 1971 Jagdkunde gelesen und das Institut für Jagdkunde der Forstlichen Forschungsanstalt geleitet.

Der Umstand, daß er nach dem Studium der Forstwissenschaft den Dr. oec. publ. erwarb, dann sich für forstliche Produktionslehre habilitierte und später im Hauptamte Leiter des im Ebersberger Park gelegenen Forstamts Anzing war, fügte es, daß er sich jagdlichen Fragen, insbesondere dem Verhältnis Wald und Wild, zuwandte. Den im 